\title{
A study of the influence of processing parameters and tool wear on elastic displacements of the technological system under face milling
}

\author{
D. Yu. Pimenov ${ }^{1}$ V. I. Guzeev ${ }^{1}$ T. Mikolajczyk ${ }^{2} \cdot$ K. Patra $^{3}$
}

Received: 15 November 2016 / Accepted: 2 May 2017 / Published online: 19 May 2017

(C) The Author(s) 2017. This article is an open access publication

\begin{abstract}
A study of the influence of processing parameters and tool wear on the total elastic displacements of the technological system is based on a mathematical model of elastic displacements during face milling. The mathematical model takes into account both plane-parallel and angular displacements of the subsystems 0 - "workpiece-device-machine table" and 1-“tool-device-z-head system." The article covers the method of experimental determination of the element compliances of the GF2171S5 milling machine technological system. Angular compliances of the spindle assembly are not listed in the milling machine technical data sheet; therefore, this work gives a method for compliance determination along the coordinate axes of the machine and angular compliances of subsystems of the technological system. The article presents the adequacy assessment of mathematical models of elastic displacements of the technological system under face milling, for different values of tool flank wear on the flank
\end{abstract}

D. Yu. Pimenov

danil_u@rambler.ru

V. I. Guzeev

gvi174@yandex.ru

T. Mikolajczyk

tami@utp.edu.pl

K. Patra

kpatra@iitp.ac.in

1 Department of Automated Mechanical Engineering, South Ural State University, Lenin Prosp. 76, Chelyabinsk, Russia 454080

2 Department of Production Engineering, UTP University of Science and Technology, Al. prof. S. Kaliskiego 7,

85-796 Bydgoszcz, Poland

3 Department of Mechanical Engineering, Indian Institute of Technology Patna, Bihta, Patna 801103, India surface. The article also presents the influences of face milling process parameters (workpiece material, cutting speed, cutting depth, the main cutting-edge angle, the cutter overhang to its diameter ratio, feed per tooth, and different values of the tool flank wear on the flank surface) on the total elastic displacements of the technological system, based on the estimated mathematical model of the elastic displacements of the technological system during face milling.

Keywords Face milling · Elastic displacement . Technological system $\cdot$ Wear

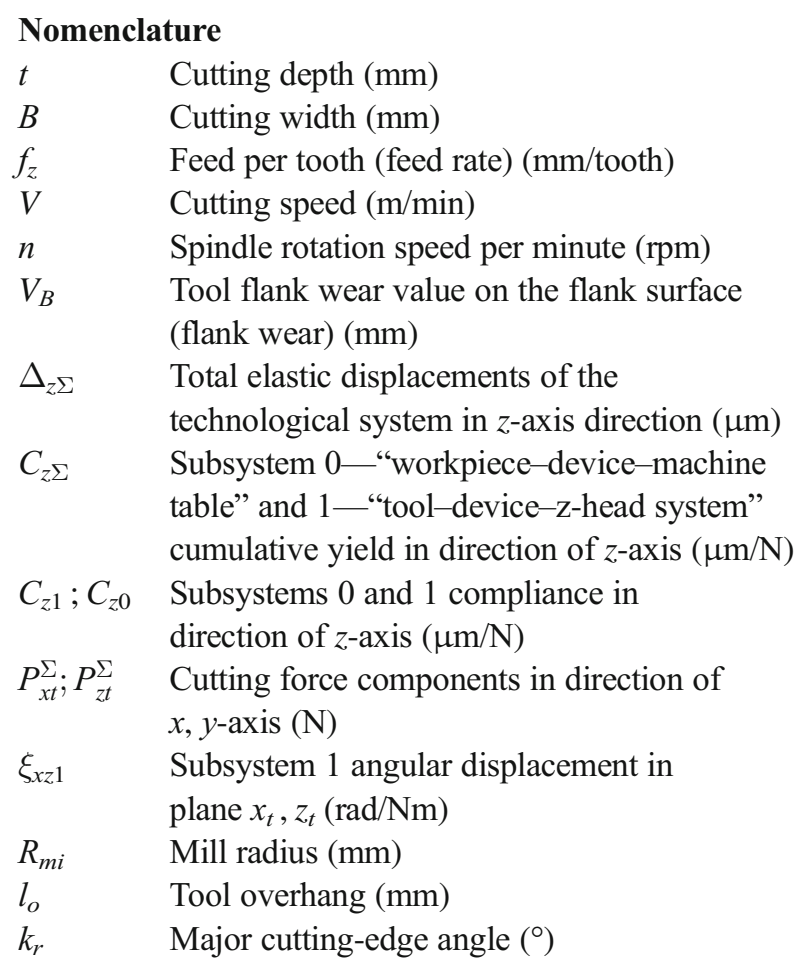


$f \quad$ Worked stock friction ratio on the clearance surface of the mill tooth cutting point

$\beta \quad$ Angle of action $\left(^{\circ}\right)$

$\beta_{1} \quad$ Shear angle $\left(^{\circ}\right)$

$\sigma_{i} \quad$ Stress intensity (intensity of material resistance to deformation) $(\mathrm{MPa})$

$d l \quad$ Element of the cutting-edge length ( $\mathrm{mm}$ )

$z_{w} \quad$ Number of teeth simultaneously involved in contact with the worked part, specified in compliance with

$\Psi_{i} \quad$ Angular coordinate of the $i$ th tooth $\left(^{\circ}\right)$

$x, y, z \quad$ Axes of the tool coordinate system

$\delta \varphi_{i} \quad$ Rotation angle around the $i$ th axis

$M_{i} \quad$ Moment of the cutting force components around the $i$ th axis

$d z_{1} \quad$ Point 1 displacement $(\mu \mathrm{m})$

$d z_{2} \quad$ Point 2 displacement $(\mu \mathrm{m})$

$L \quad$ Distance between points 1 and $2(\mathrm{~mm})$

$\chi_{z x 1} \quad$ Subsystem 1 rotation angle $\left(\operatorname{rad} 10^{-3}\right)$

$H B \quad$ Brinell hardness

$\gamma, \alpha \quad$ Rake and back angles $\left(^{\circ}\right)$

$r_{o} \quad$ Corner radius of the cutting edge $(\mathrm{mm})$

$z \quad$ Number of milling cutter teeth

$\lambda \quad$ Main cutting-edge inclination $\left(^{\circ}\right)$

$k_{r 1} \quad$ Minor cutting-edge angle $\left(^{\circ}\right)$

$k \quad$ Number of experiment repetitions

\section{Introduction}

In the process of face milling, not only the process parameters but also elastic deformations of the technological system (tool-workpiece-machine tool assembly) influence the dimensional accuracy and the surface topography of the machined parts [1-7]. The elastic deformation error of the technological system mainly depends on the influence of unstable cutting forces. The cutting force, in turn, is generally determined by the following technological factors: cutting depth, cutting width, feed per tooth, and cutting speed. The value of tool wear on the flank surface of the milling tooth can also influence the cutting force that results the elastic displacements of the technological system. However, how and to what extent these factors the mechanical properties of the workpiece and the cutting-edge angle affect the elastic displacements of the technological system at different values of tool wear on the flank surface have been insufficiently studied.

Kolev and Gorchakov [4], and Medvedev [5] were the pioneers to include technological system deformations in their works to determine machining errors in the face milling process.

Thereafter, few other researchers considered deflections of technological system (spindle-tool-workpiece-fixture) in the analysis of quality and productivity of face milling process.
Radulescu et al. [6] analyzed tool-workpiece displacement, cutting forces, and chip load variation and concluded that variable speed face milling could be robust with respect to cutting process dynamics. Denkena et al. [7, 8] presented models for shape deviations (material height deviations, transition deviation, and surface roughness deviation) considering cutting forces and cutting tool deflections in the face milling of hybrid structures. The predicted models were validated with experimental results. It was shown that tool holder had significant influence on the surface shapes. However, tool wear influence on shape deviations was not considered in these works. Badar et al. [9] described an adaptive sampling procedure to reduce sample size for estimating straightness and flatness errors in end milling and face milling processes considering the effects of cutting parameters and support conditions. The article of Hadad and Ramezani [10] presented a method for regular structuring and special patterning of workpiece surface applying face milling process. Mathematical simulations which described the cutting tool geometry and its position during machining could be used to optimize the surface quality for given face milling parameters. Huang and Hoshi $[11,12]$ optimized the device design, taking into consideration the thermal deformation to improve flatness accuracy in face milling of plate-shaped workpieces. Tai et al. [13] proposed a method of milling scheduling to reduce the surface height change based on the high-definition metrology (HDM). In other works, Tai et al. [14, 15] proposed approaches to improve the flatness of the surface obtained by face milling, based on 3-D holographic laser measurement and ways of feed rate optimizing. Franco et al. [16] reported surface imperfection in face milling was caused by undeformed chip thickness variation, fluctuation of feed rate, and height deviation during machine tool axis displacement. In the course of experiment, Yi et al. [17] determined deviation from flatness of surfaces processed by face milling with different feeds, cutting speeds, and axial depths. Sheth and George [18] showed the effects of spindle speed, feed, and cutting depth on the surface flatness and roughness in face milling of WCB material. However, the effects of tool wear on surface flatness were not considered in these works.

Kaldestadet et al. [19] and Tyapin et al. [20] showed methods for tool linear deflection compensation and vibration reduction in face milling of aluminum with an industrial robot. Their research efforts demonstrated that both the robot stiffness value and the tool path could be adjusted to counteract the tool deflection during milling. Yi et al. [21] presented a method of prebending the workpiece caused by fixture in face milling to reduce surface error. The article of Yi et al. [22] showed that stretched fixation improved the surface quality, flatness, and residual stress of face milled $6061 \mathrm{~T} 6$ aluminum alloy. Davoudinejad et al. [23] considered important issues such as processing strategy, intermediate control of spindle, and tool wear compensation to improve surface flatness. 


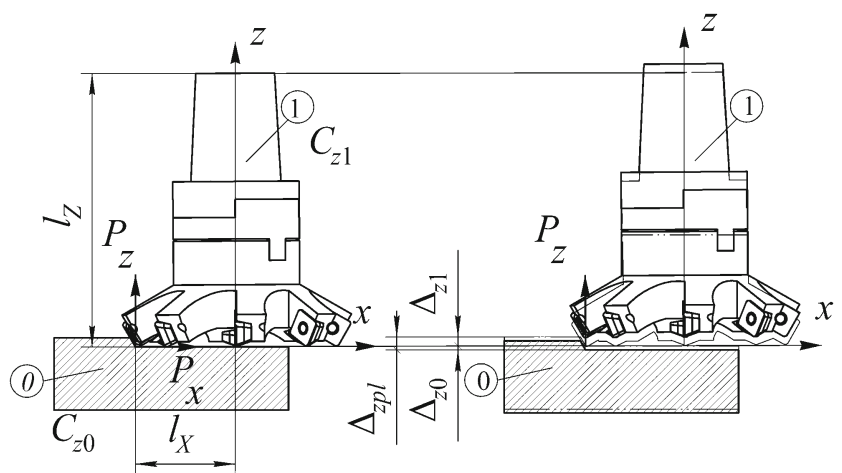

Fig. 1 Design scheme of plane-parallel elastic displacements along the technological system in $z$-axis in face milling: $l_{z}=l_{o}$-the tool overhang; $C_{z 0}$ and $C_{z 1}$-compliances of subsystems 0 и 1 in direction of $z$-axis; $\Delta_{z 0}$ and $\Delta_{z 1}$-plane-parallel elastic displacements of subsystems 0 и 1 in direction of $z$-axis

Nguyen et al. [24, 25] applied HDM enabled surface variation control using cutting load balancing and cutter spindle deflection in face milling processes. They showed that the approaches of the various feed rate and side milling cutter path planning are the most appropriate to monitor the surface variations. To reduce the flatness error of the flexible plate due to its deflection during conventional face milling, simultaneous double-sided milling with speed difference and with synchronized single-tooth cutters was proposed by Shamoto et al. [26] and Mori et al. [27], respectively.

Gu et al. [28] presented a new model for predicting surface flatness errors of the face milling process. The model included the effects of machining conditions, elastic deformation of the cutter spindle and workpiece fixture assemblies, static spindle axis tilt, and axially inclined tool path. They also proposed a new method called equivalent flexibility coefficient to compute elastic deformations of machining system at the point of cutting force applications. But measurement of flatness error using elastic deformation and spindle axis tilt could be inflated by inclusion of surface roughness. Liu and Zou [29] predicted the surface flatness errors in the course of face milling, using the traditional trial-and-error method. Their work emphasized on the optimization of machining parameters to minimize surface deformation under machining loads. Nguyen et al. [30] proposed a method to monitor spindle tilt and cutter spindle deflection using surface data measured by high-definition metrology. Cutter spindle deflection was used to correlate the machine conditions such as loose and worn bearing for process diagnosis.

Many of the above studies focused on the machine tool and cutter impact on machining errors. Most of the works were built on an experimental solution to the problem of estimating accuracy parameters of face milled surfaces. In this case, it is impossible to choose cutting data to ensure specified accuracy. However, only few studies concentrated on predicting elastic deformations for different cutting conditions. However, they did not take into account the effect of tool wear on the elastic deformations of the technological systems in machining process.

Different researchers solved the problem of determining the elastic displacements of the technological system elements in different ways. For example, Medvedev [31] took total compliance of the technological system. On the other hand, Bazrov $[32,33]$ divided the technological system into number of nodes, but it is quite difficult to determine compliance of each node.

These deficiencies have been eliminated in the analytic model for elastic displacement proposed by Pimenov et al. [34]. Their model took into account both the elastic deformation of the axial table-device-part subsystem and that of the tool-spindle-spindle assembly subsystem. But the most important feature of the model of Pimenov et al. [34], in contrast to the others above, was the consideration of the angular deformation of the machine spindle assembly (the cutter rotation angle), which arose due to the cutter force loading during machining. In addition, the works in ref. $[35,36]$ considered the effect of the tooth flank wear of the face mill cutting forces [36]. The objective of the present work is to further study the impact of tool wear on the elastic deformation of the technological systems of the face milling process. The article proposes a mathematical model of the total elastic deformation of the technological system considering the influences of face
Fig. 2 Design scheme of angular elastic displacements of the technological system under face milling. a $M_{y P_{x}^{\Sigma}}>M_{y P_{z}^{\Sigma}}$. b $M_{y P_{x}^{\Sigma}}<M_{y P_{z}^{\Sigma}} ; x_{x z 1}$ - subsystem 1 rotation angle; $\xi_{x z 1}$-subsystem 1 angular compliance; $l_{x}=R_{m i}$ the tool overhang in direction of $x$-axis (a)

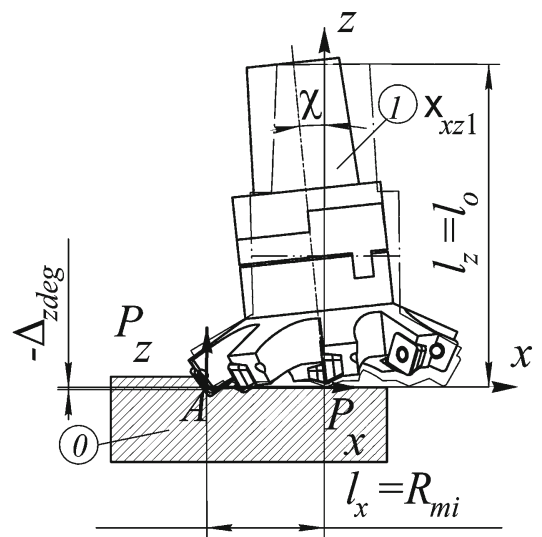

(b)

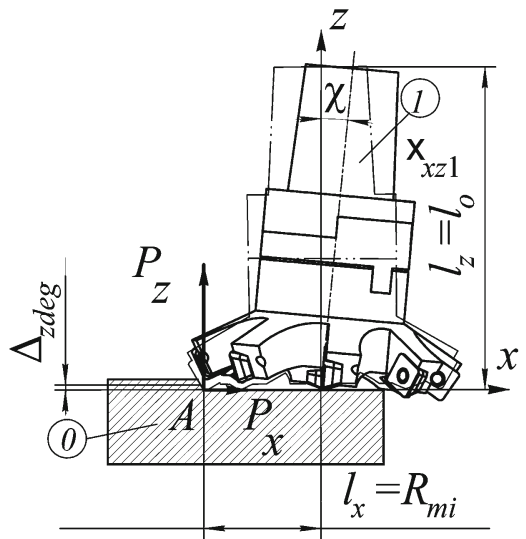




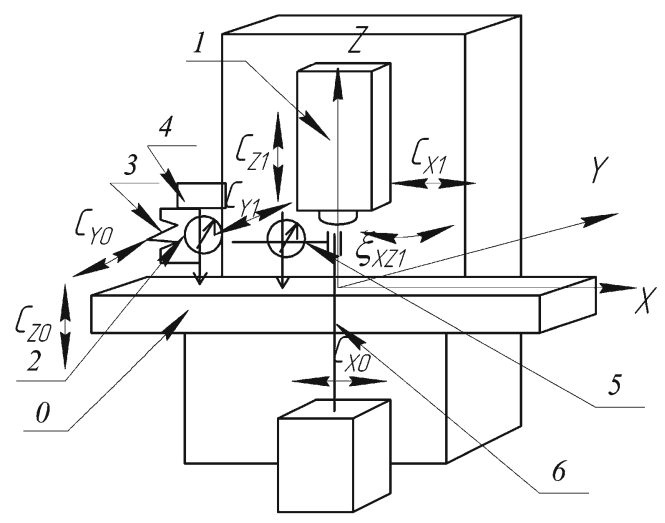

Fig. 3 Compliances of "machine table" and "spindle group" subsystems: 0 -machine table; 1 -spindle group; 2 - the dial indicator; 3 dynamometer; 4-the load; 5-the indicator; 6 - the rack

milling parameters (work-piece material, cutting speed, cutting depth, the main cutting-edge angle, the cutter overhang to its diameter ratio, feed per tooth, and tool flank wear. The adequacy of the proposed mathematical models of elastic displacements has been experimentally assessed.

\section{Theory}

\subsection{Mathematical model of elastic displacements of technological system considering tool wear}

The present mathematical model for elastic displacements of the technological system during face milling is the extended form of model developed by Pimenov et al. [34]. This model includes cutting force constituents considering wear on the flank surface of the face mill teeth, obtained in the work of Guzeev and Pimenov [35]. The cutting force model is based on the generated stresses on the flank surface of face mill teeth as given in the work of Pimenov and Guzeev [36].

A great number of errors influence dimension accuracy and machined surface roughness during machining. For example, a mathematical model of elastic displacements of the technological system in the $z$-axis direction, in respect of plane-parallel and angular yield, obtained in works of Pimenov et al. [34], is used for the face milling accuracy criterion:

$\Delta_{z \Sigma}=C_{z \Sigma} P_{z t}^{\Sigma}+R_{m i}\left(P_{z t}^{\Sigma} R_{m i}-P_{z t}^{\Sigma} l_{o}\right) \xi_{x z 1}$,

where $C_{z \Sigma}$ is subsystem 0- "workpiece-device-machine table", and 1-"tool-device-z-head system" cumulative yield in the direction of $z$-axis; $P_{x t}^{\Sigma}$ and $P_{z t}^{\Sigma}$ are cutting force components, obtained in the work of Guzeev and Pimenov [35]; $\xi_{x z 1}$ is subsystem 1 angular displacement in plane $x_{t} z_{t} ; R_{m i}$ is the mill radius; $l_{o}$ is the tool overhang; and $C_{z \Sigma}, \xi_{x z 1}$ is axial and angular yield.

We will use dependencies for the cutting force components model of Guzeev and Pimenov [35], influencing the straight line portion of the mill tooth:

$$
\begin{aligned}
P_{x t}^{\Sigma}= & 1,08 f_{z} R_{m i} \operatorname{tg} k_{r} \sum_{i=1 R_{m i}\left(1-\cos k_{r}\right)}^{z_{w}} \frac{\sigma_{i}}{\sin \beta_{1}} \cos \beta \sin \psi_{i} \cos \psi_{i} \cos k_{r} d l+\frac{R_{m i} f \sigma_{i}}{\cos k_{r}} \sum_{i=1 R_{m i}\left(1-\cos k_{r}\right)}^{z_{w}} \cos \psi_{i}\left(0,41 V_{B}+0,59 \frac{f_{z}}{2}\left(1-e^{-2 \cdot V_{B} / f_{z}}\right)\right) d l- \\
& -1,08 f_{z} R_{m i} \operatorname{tg} k_{r} \sum_{i=1 R_{m i}\left(1-\cos k_{r}\right)}^{z_{r}} \frac{\sigma_{i}}{\sin \beta_{1}} \sin \beta \sin ^{2} \psi_{i} \cos k_{r} d l-\frac{R_{m i} \sigma_{i}}{\cos k_{r}} \sum_{i=1 R_{m i}}^{z_{w}} \int_{\left.-\cos k_{r}\right)}^{t} \sin \psi_{i}\left(0,41 V_{B}+0,59 \frac{f_{z}}{2}\left(1-e^{-2 \cdot V_{B} / f_{z}}\right)\right) d l
\end{aligned}
$$

$$
\begin{aligned}
P_{z t}^{\Sigma} & =1,08 f_{z} R_{m i} t g k_{r} \sum_{i=1 R_{m i}\left(1-\cos k_{r}\right)}^{z_{w}} \frac{\sigma_{i}}{\sin \beta_{1}} \cos \beta \sin \psi_{i} \cos k_{r} d l \\
& +\frac{R_{m i} \sigma_{i}}{\cos k_{r}} \sum_{i=1 R_{m i}\left(1-\cos k_{r}\right)}^{z_{w}}\left(0,41 V_{B}+0,59 \frac{f_{z}}{2}\left(1-e^{-2 \cdot V_{B} / f_{z}}\right)\right) d l,
\end{aligned}
$$

where $k_{r}$ is the cutting-edge angle; $\mathrm{t}$ is cutting depth; $f_{z}$ is feed per tooth; $f$ is the worked stock friction ratio on the clearance surface of the mill tooth cutting point; $\beta$ is the angle of action; $\beta_{1}$ is the angle of displacement; $\sigma_{i}$ is stress intensity (intensity of material resistance to deformation [36, 37]); $d l$ is element of the cutting-edge length; $V_{B}$ is the tool flank wear value on the flank surface [36]; $Z_{w}$ is a number of teeth simultaneously in contact with the worked part, specified in compliance with [35]; $\Psi_{i}$-angular coordinate of the $i$ th tooth; and $i=x, y, z$ are axes of the tool's coordinate system.

The first term in expression (1) takes into account the planeparallel elastic displacement of the technological system (see Fig. 1):

$\Delta_{z p l}=C_{z \Sigma} P_{z t}^{\Sigma}$,

The second term in expression (1) takes into account the angular elastic displacement of the technological system (see Fig. 2):

$\Delta_{\text {zdeg }}=R_{m i}\left(P_{z t}^{\Sigma} R_{m i}-P_{x t}^{\Sigma} l_{o}\right) \xi_{x z 1}$

The design scheme of elastic displacements in the course of face milling of the system comprising subsystems 0-"workpiece-device-machine table" and 1-“tool-device-z-head system" is as follows (Fig. 1). 
(a)

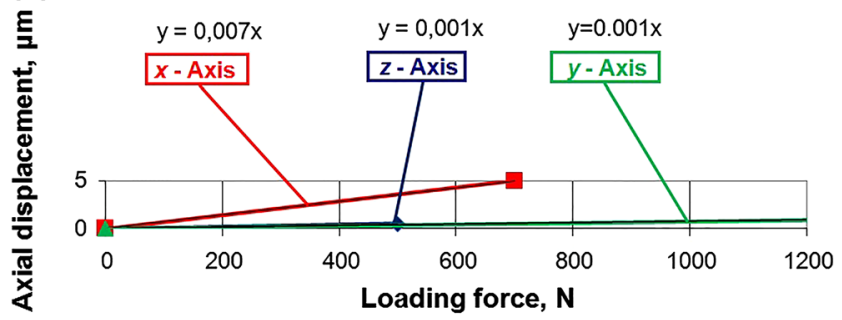

(b)

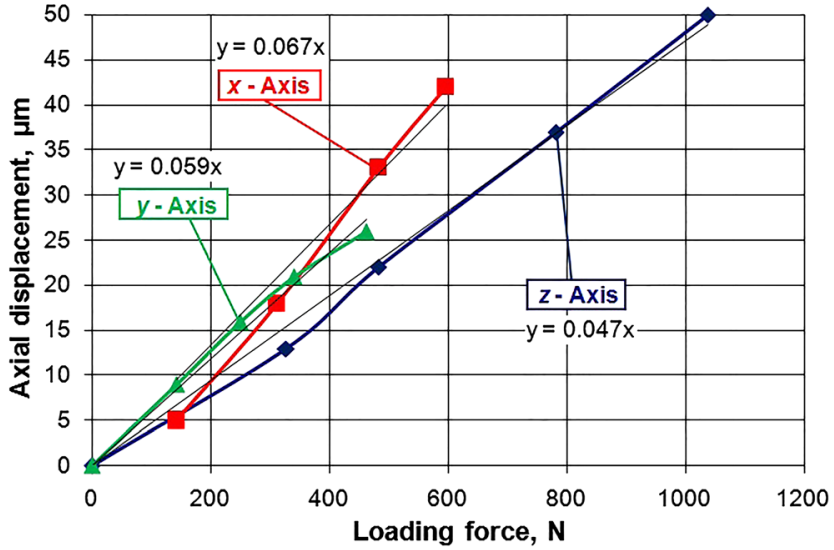

Fig. 4 Experimental results of static axial compliance: $x$-axis, $y$-axis, and $z$-axis for different loading

The plane-parallel elastic displacements of subsystems 0 and 1 in direction of $z$-axis are defined by the formulas:

$\Delta_{z 0}=C_{z 0} P_{z}^{\Sigma}$ and $\Delta_{z 1}=C_{z 1} P_{z}^{\Sigma}$

The rotation angle $\chi$ is defined through the cutting force and angular compliance (Fig. 2):

$\chi_{x z 1}=M \xi_{x z 1}$.

Expression (1) is the mathematical model of elastic displacements due to the plane-parallel displacements and angular rotation of subsystems in the technological system.

\section{Experiments}

\subsection{Experimental determination of the element compliances of the GF2171S5 milling machine technological system}

Considering effectiveness from the point of view of mathematical apparatus simplification of such an (a)

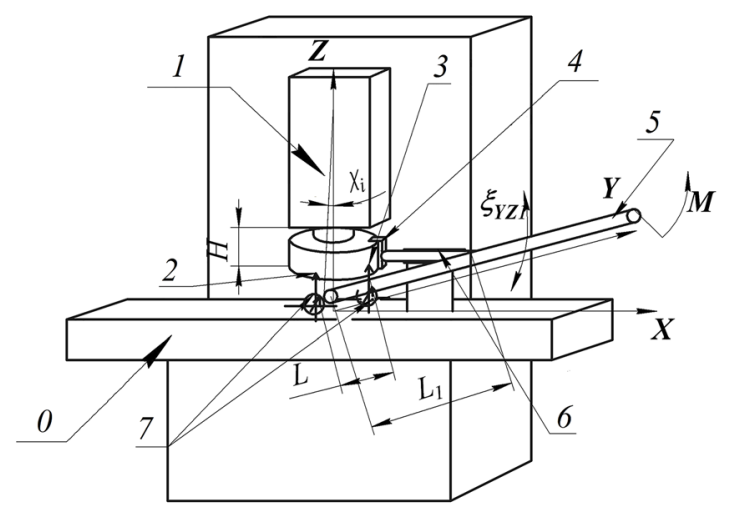

(b)

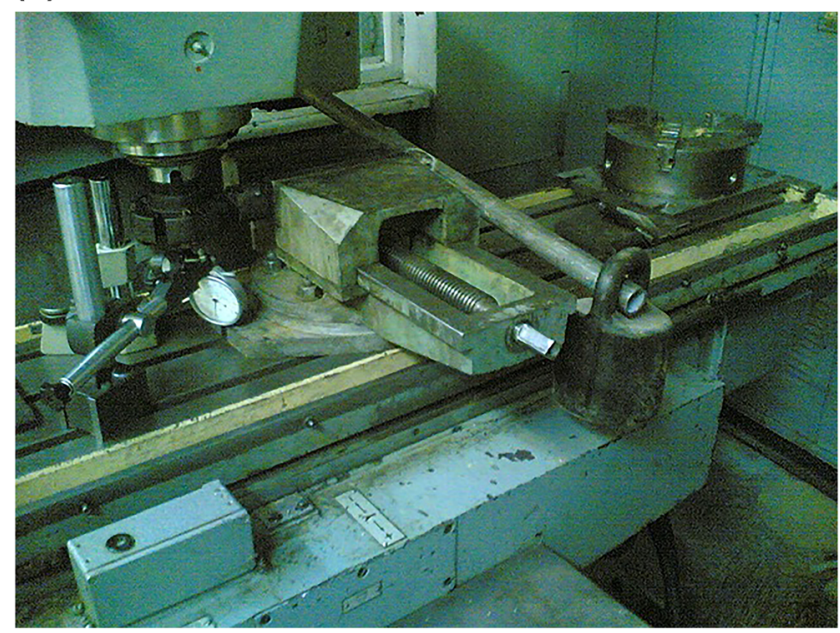

Fig. 5 Experimental procedure for machine spindle group angular compliance. a Measurement scheme. b Experimental stand: 0machine table; 1 - spindle group; 2 - point $1 ; 3$ - point 2; 4-key; 5crossbar; 6-guide bushing; 7-dial indicator

approach, the present work assumes this approach for face milling conditions.

Here, using an analogy with the turning, we pay attention to the following subsystems:

Subsystem 0: "workpiece-device-machine table"

Subsystem 1: "tool-device-spindle group"

To calculate elastic displacements, the axial and angular compliances of subsystems of the technological system are required (see Figs. 1 and 2).

Under the cutting force elements of the technological system, we get two types of elastic displacement: displacements along the coordinate axes and angular movements around respective axes. Angular compliance of

Table 1 Axial compliances of subsystems 1 and 0

Subsystem 0: "machine table"

Compliance $C y_{0}, \mu \mathrm{m} / \mathrm{N}$ Compliance $C x_{0}, \mu \mathrm{m} / \mathrm{N}$ Compliance $C z_{0}, \mu \mathrm{m} / \mathrm{N}$

0.007

0.001

Subsystem 1: "spindle group"

Compliance $C y_{1}, \mu \mathrm{m} / \mathrm{N}$ Compliance $C x_{1}, \mu \mathrm{m} / \mathrm{N}$ Compliance $C z_{1}, \mu \mathrm{m} / \mathrm{N}$

0.001

0.00

0.067

0.059

0.047 


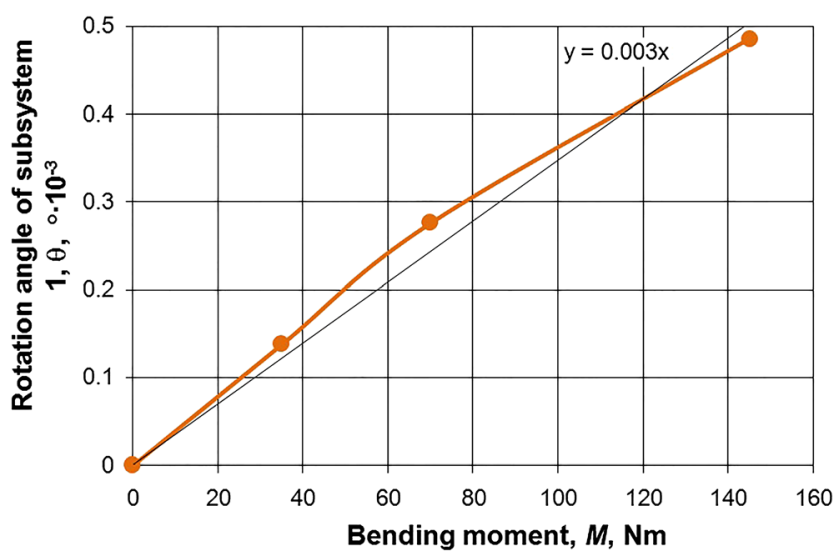

Fig. 6 Experimental results of the static angular compliance of the machine subsystem 1 "spindle group"

the spindle assembly is not specified in the milling machine technical data sheet. In this regard, experimental studies were performed to determine these two types of compliance.

The experiments consisted of measuring static compliance of the technological system. The machine components were loaded with forces in axial directions, movements in these directions were determined, and these values specified the technological system compliance in respective axial directions.

To determine the angular compliance, loading was performed by the force moment, and angular displacement was determined by the linear displacement of 2 points on the same plane.

Due to cutting forces, the machine components receive two types of elastic displacement: displacement along coordinate axes and angular displacement around corresponding axes.

Experimental studies of the milling machine compliance were carried out in three directions.

\subsubsection{Definition of displacements along coordinate axes}

Method There are various methods for determining machine tool stiffness: static, dynamic, etc. [38]. The paper describes the applied static method of determining axial compliances of the GF2171S5 milling machine subsystems. Compliance in the $i$-axis direction is determined by the ratio:

$C_{i}=\Delta_{i} / P_{i}$,

where $\Delta_{i}$-elastic displacements in the $i$ th axis direction $(i=x, y, z)$; and $P_{i}$-constituent of the cutting force in the $i$ th axis direction.

Equipment Measurements were performed on the GF2171S5 $\mathrm{CNC}$ milling machine. The equipment consists of two measuring racks with two dial indicators, with a scale division of $1 \mu \mathrm{m}$, a dynamometer with a dial indicator with a scale division of $0.01 \mathrm{~mm}$, and load weights 10 and $20 \mathrm{~kg}$.

Measurement schemes Measurements of compliances of subsystems 0 "machine table" and 1 "spindle group" are shown in Fig. 3 To determine the appropriate compliance in the $x, y, z$ direction, force loading was carried out corresponding to the face milling force level, and in the opposite direction to the force loading, the subsystem movement readings were taken off indicator 5 installed in rack 6 . The load value was recorded by dynamometer 3 with dial indicator 2 . The dynamometer was loaded with load 4 . The dynamometer was precalibrated, and its compliance was equal to $0.7 \mu \mathrm{m} / \mathrm{N}$.

The results of experiments on determining the static compliance of subsystems 1 and 0 according to the scheme (see Fig. 1) are presented in Fig. 4.

Table 1 presents the results of experiments of $x, y$, and $z$ compliance in corresponding directions.

Thus, the axial compliances of the "machine table" subsystem 0 are one to two orders less than that of the "spindle group" subsystem 1, whereas the lowest compliance value is in the $z$-axis direction. The executable dimension is formed by face milling in this very direction.

\subsubsection{Angular compliances of subsystem 1 in the planes $Z X$ and $Z Y$}

Angular compliances of the spindle assembly are not listed in the milling machine technical data sheet. Therefore, along with experimental method of determining the axial compliances in the work, the experimental method for angular

Table 2 Axial compliances of the "spindle group" subsystem 1

\begin{tabular}{|c|c|c|c|c|c|c|}
\hline $\begin{array}{l}\text { Bending } \\
\text { moment, } M \text {, } \\
\text { Nm }\end{array}$ & $\begin{array}{l}\text { Point } 1 \\
\text { displacement, } \\
d z_{1}, \mu \mathrm{m}\end{array}$ & $\begin{array}{l}\text { Point } 2 \\
\text { displacement, } \\
d z_{2}, \mu \mathrm{m}\end{array}$ & $\begin{array}{l}\text { The distance between } \\
\text { points } 1 \text { and } 2, L, \mathrm{~mm}\end{array}$ & $\begin{array}{l}\text { Rotation angle, } \\
\chi=\operatorname{atg}\left(\left(d z_{2}-d z_{1}\right) / \mathrm{L}\right) \\
10^{-3}, \operatorname{rad}\end{array}$ & $\begin{array}{l}\text { Rotation } \\
\text { angle, } \chi, \\
10^{-3}, 0\end{array}$ & $\begin{array}{l}\text { Rotation compliance of } \\
\text { subsystem } 1, \xi, 10^{-3}, \mathrm{rad} / \mathrm{Nm}\end{array}$ \\
\hline 0 & 0 & 0 & 105 & 0 & 0 & 0 \\
\hline 35 & -5.5 & 9 & 105 & 0.1381 & 7.914 & 3.943 \\
\hline 70 & -9 & 20 & 105 & 0.27619 & 15.828 & 3.944 \\
\hline 145 & -14 & 37 & 105 & 0.48571 & 27.835 & 3.348 \\
\hline
\end{tabular}


Table 3 Chemical composition of TT10K8-B hard alloy of titan and tantalum group

Chemical composition in \%

\begin{tabular}{llll}
\hline $\begin{array}{l}\text { Tungsten } \\
\text { carbide, WC }\end{array}$ & $\begin{array}{l}\text { Titanium } \\
\text { carbide, TiC }\end{array}$ & $\begin{array}{l}\text { Tantal } \\
\text { carbide, TaC }\end{array}$ & Cobalt, Co \\
\hline 82 & 3 & 7 & 8 \\
\hline
\end{tabular}

compliances was developed, and GF2171S5 machine specific data were obtained.

The table compliance was very small, so the table angular compliance was not measured. The spindle group and cutter were both rotated. Therefore, the angular compliance was defined for subsystem 1 .

Method The paper covers the static method of determining the angular compliances of the GF2171S5 milling machine subsystems. The angular compliance in the planes $\mathrm{ZX}$ and $\mathrm{ZY}$ is determined by the following ratio [32]:

$\xi_{i}=\frac{\delta \chi_{i}}{M_{i}}$

where $\delta_{x_{i}}$-the rotation angle around the $i$ th axis $(i=x, y, z)$; and $M_{i}$-the moment of the cutting force components around the $i$ th axis.

Equipment Measurements were performed on the GF2171S5 CNC milling machine in the South Ural State University in the Laboratory of the Department of Automated Mechanical Engineering. The equipment consisted of two measuring racks with two dial indicators, with a scale division of $1 \mu \mathrm{m}$, a dynamometer with a dial indicator with a scale division of $0.01 \mathrm{~mm}$, and load weights 10 and $20 \mathrm{~kg}$, and a special device to control the angular compliance of the spindle head stock.

Measurement schemes Measurements of angular compliance of subsystem 1 "spindle group" are shown in Fig. 5a. To determine the angular compliance of the spindle rotation in the planes $\mathrm{ZX}$ and $\mathrm{ZY}$, a special device was made to create the cutter bending moment in the direction of these planes (see Fig. 5b).

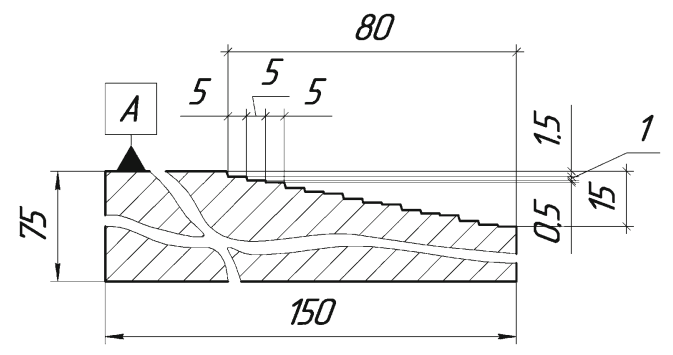

Fig. 7 Part with 15 steps and gauge length A
Table 4 Cutting conditions for various treatment stages of face milling

\begin{tabular}{llllll}
\hline No. & Face milling \\
stage & $\begin{array}{l}\text { Cutting } \\
\text { depth, } \\
t, \mathrm{~mm}\end{array}$ & $\begin{array}{l}\text { Feed per } \\
\text { tooth, } \\
f_{z}, \mathrm{~mm} / \\
\text { tooth }\end{array}$ & $\begin{array}{l}\text { Cutting } \\
\text { speed, } \\
V \\
\mathrm{~m} / \mathrm{min}\end{array}$ & $\begin{array}{l}\text { Spindle } \\
\text { rotation, } \\
n, \mathrm{rpm}\end{array}$ \\
\hline 1 & Semifinishing & 1.5 & 0.25 & 163 & 510 \\
2 & $\begin{array}{l}\text { Finishing } \\
3\end{array}$ & 1.0 & 0.16 & 210 & 670 \\
& $\begin{array}{c}\text { Final } \\
\text { polishing }\end{array}$ & 0.5 & 0.11 & 250 & 800 \\
\hline
\end{tabular}

The device consisted of the guide bushing, the crossbar of t-shaped welded tubular beams, the bushing with the key way, and the key.

The experimental results to determine the static angular compliance of subsystems 1 are represented in Fig. 6.

Table 2 shows the values of the bending moment and rotation angles.

Thus, the angular compliance of the machine subsystem 1 "spindle group" is equal to $\xi_{X Z 1}-3.310^{-6} \mathrm{rad} / \mathrm{Nm}$. Considering both compliance types, the axial and angular compliances may be considered when setting up face mills as the tool axial and angular displacement relative to the workpiece. The experimental methodology described here is also applicable to other milling machines.

\subsection{Adequacy assessment of the mathematical model of elastic displacements for different wear values}

The experiments were carried out to assess the adequacy of the mathematical model of the elastic displacements of the technological system in face milling operations for different values of the tool flank wear. Machining was carried out on the GF2171S5 machine with the FMS-3000 rack without cooling, using a tool with the cutting edge of TT10K8-B material (the composition of the TT10K8-B hard alloy of titan and tantalum group, according to GOST 3882-74, shown in Table 3 [39]), with the following parameters: the cutter diameter $-D=100 \mathrm{~mm}$; the major cutting-edge angle $-k_{r}=60^{\circ}$;

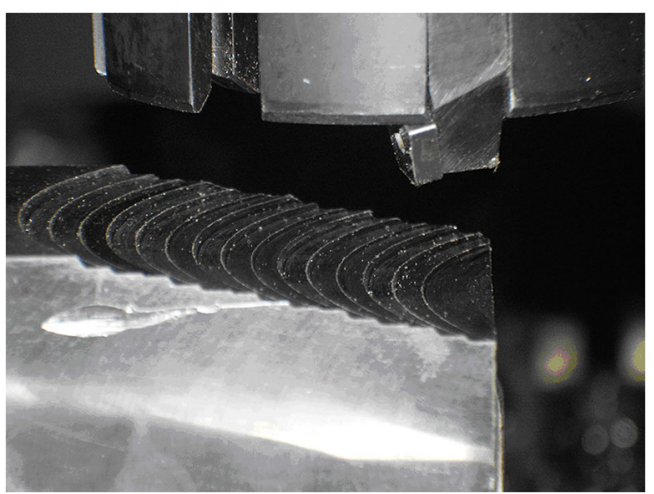

Fig. 8 Workpiece and face milling cutter with the flank wear value $V_{B}=0.8 \mathrm{~mm}$ 


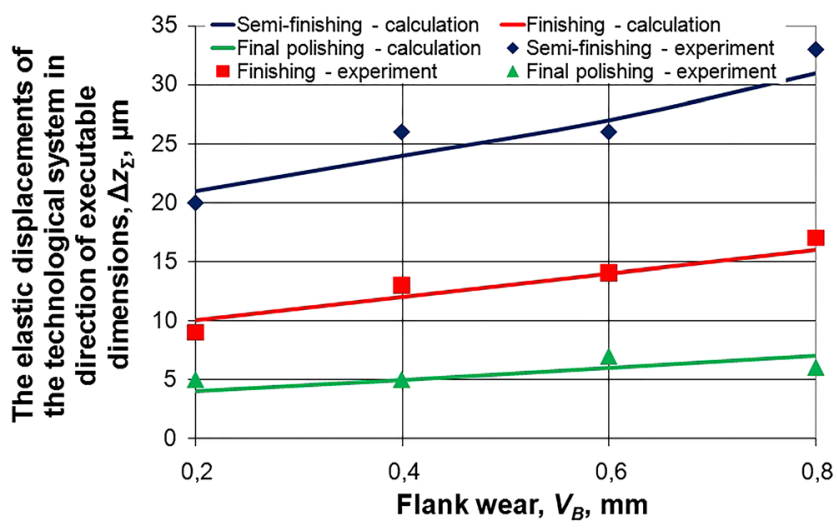

Fig. 9 Elastic displacements of technological system in the direction of executable dimensions depending on the face milling cutter's wear

the rake angle $-\gamma=-5^{\circ}$; the back angle $-\alpha=8^{\circ}$; the minor cutting-edge angle $-k_{r l}=12^{\circ}$; the number of teeth- $z=1$; and the main cutting-edge slope angle $-\lambda=5^{\circ}$. As a workpiece, structural carbon steel 45 [40] of dimension of $140 \times 75 \times 75 \mathrm{~mm}$ was used. The workpiece's hardness was measured using the TB 5004-03 Brinell indenter: HB190.

The gauge length was arranged directly on the machine, where the step deviations were measured as shown in Fig. 7.

The cutting conditions selected for various treatment stages, according to the handbook [41], are given in Table 4.

Thus, consistently performing semifinishing, finishing, and final polishing stages, we get the part with steps of $1.5,1$, and $0.5 \mathrm{~mm}$. The steps were made using a single-tooth milling cutter, with consecutive growth of value of the flank wear of the tooth cutter as follows: $0,0.2,0.4,0.6$, and $0.8 \mathrm{~mm}$, i.e., at the first three stages $V_{B}=0 \mathrm{~mm}$ (non-worn cutter) and at the following three steps $V_{B}=0.2,0.4 \mathrm{~mm}$, etc.

Thus, consistently performing semifinishing, finishing, and final polishing stages, with different values of the flank wear of the cutter tooth, we get the part with steps of 1.5, 1, and $0.5 \mathrm{~mm}$ (Fig. 8).

The height difference between the planes and the reference plane gives the value of the elastic pressing out of the technological system from the part.

Table 5 Processing parameters for calculation of elastic displacements of the technological system, considering tool wear

\begin{tabular}{lll}
\hline Item no. & Initial data name & Initial data values \\
\hline 1 & Machined stock & $\begin{array}{c}45 \text { steel; } 40 \mathrm{H} \text { steel; } 18 \mathrm{HNVA} \\
\text { steel }\end{array}$ \\
& & $150 ; 300 ; 450$ \\
3 & Cutting speed, $V, \mathrm{~m} / \mathrm{min}$ & $1 ; 2 ; 4$ \\
4 & Cutting depth, $t, \mathrm{~mm}$ & $0.25 ; 1.0 ; 2.0$ \\
5 & Cutter overhang to & diameter ratio, $l_{0} / D$ \\
4 & Feed per tooth, $f_{z}, \mathrm{~mm} /$ tooth & $0.1 ; 0.2 ; 0.3 ; 0.4$ \\
& Flank wear, $V_{B}, \mathrm{~mm}$ & $0 ; 0.2 ; 0.4 ; 0.6 ; 0.8 ; 1.0 ; 1.2 ;$ \\
\end{tabular}

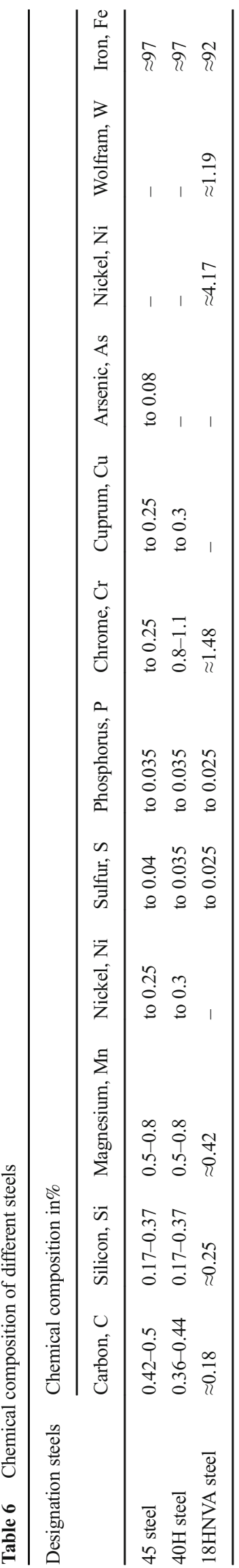


a) $f_{z}=0.1 \mathrm{~mm} /$ tooth

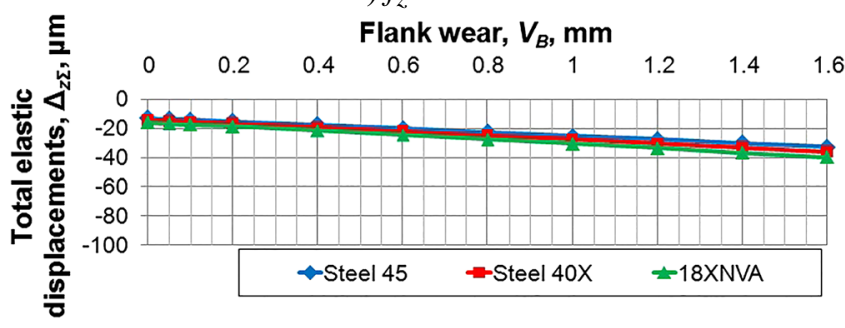

c) $f_{z}=0.3 \mathrm{~mm} /$ tooth

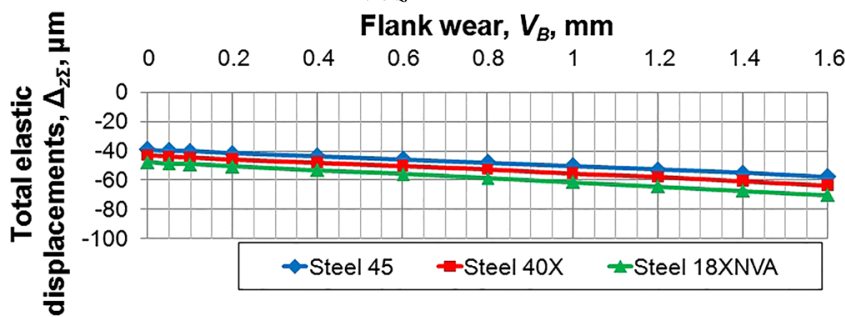

b) $f_{z}=0.2 \mathrm{~mm} /$ tooth

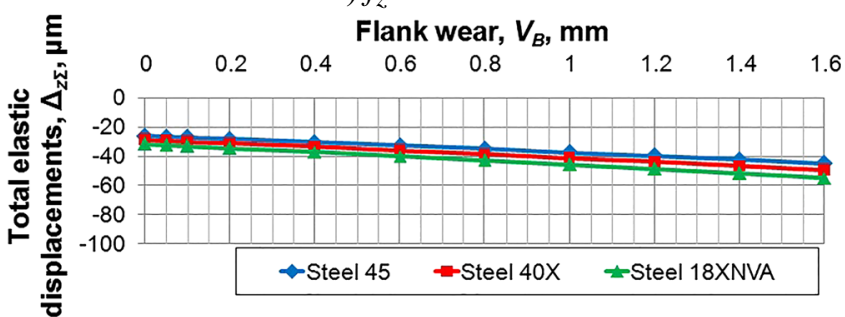

d) $f_{z}=0.4 \mathrm{~mm} /$ tooth

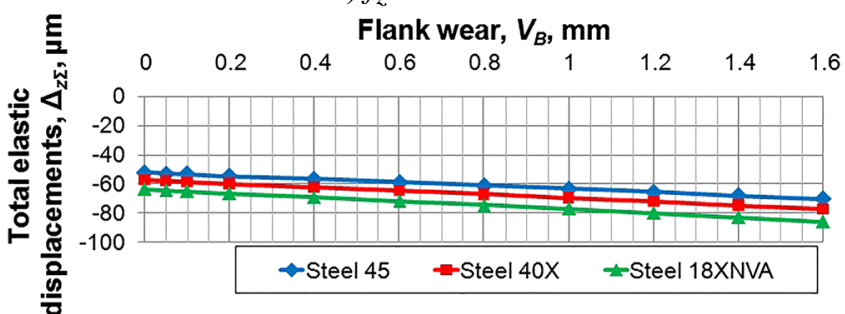

Fig. 10 Dependence of total elastic displacements on direction of executable dimension on the flank wear value for different treated materials $\left(D=200 \mathrm{~mm}, z=20, B=120 \mathrm{~mm}, t=1 \mathrm{~mm}, l o / D=2, k r=60^{\circ}, V=150 \mathrm{~m} / \mathrm{min}\right)$

All the experiments had five times repetitions. The homogeneity of sampling variances was verified with Cochran's criterion.

Fisher's ratio test was used to assess the adequacy of the mathematical model of the elastic displacements of the technological system in face milling operations, for different values of wear (7).

Figure 9 shows the graphs of the elastic displacements of the technological system values for different lengths of the worn places of the cutter flank wear, calculated with the estimated model (1), and the experimental points. The cutting modes for respective processing stages are shown above.

As can be seen, the elastic displacement of the technological system increases with the wear increase from 0.2 to
$0.8 \mathrm{~mm}$ and its values are as follows: for the semifinishing stage $-12 \mu \mathrm{m}$; for the finishing stage $-8 \mu \mathrm{m}$; and for the final polishing stage $-3 \mu \mathrm{m}$.

\section{Results and discussion}

\subsection{Estimation of total elastic displacement}

According to Eq. (1), the total displacements of the technological system in the direction of the executable dimension $\Delta_{z \Sigma}$ were determined as the sum of plane-parallel displacement $\Delta_{Z}$ and angular displacement $\Delta_{z \text { deg }}$. The total displacements were calculated at different tool wear for the given the
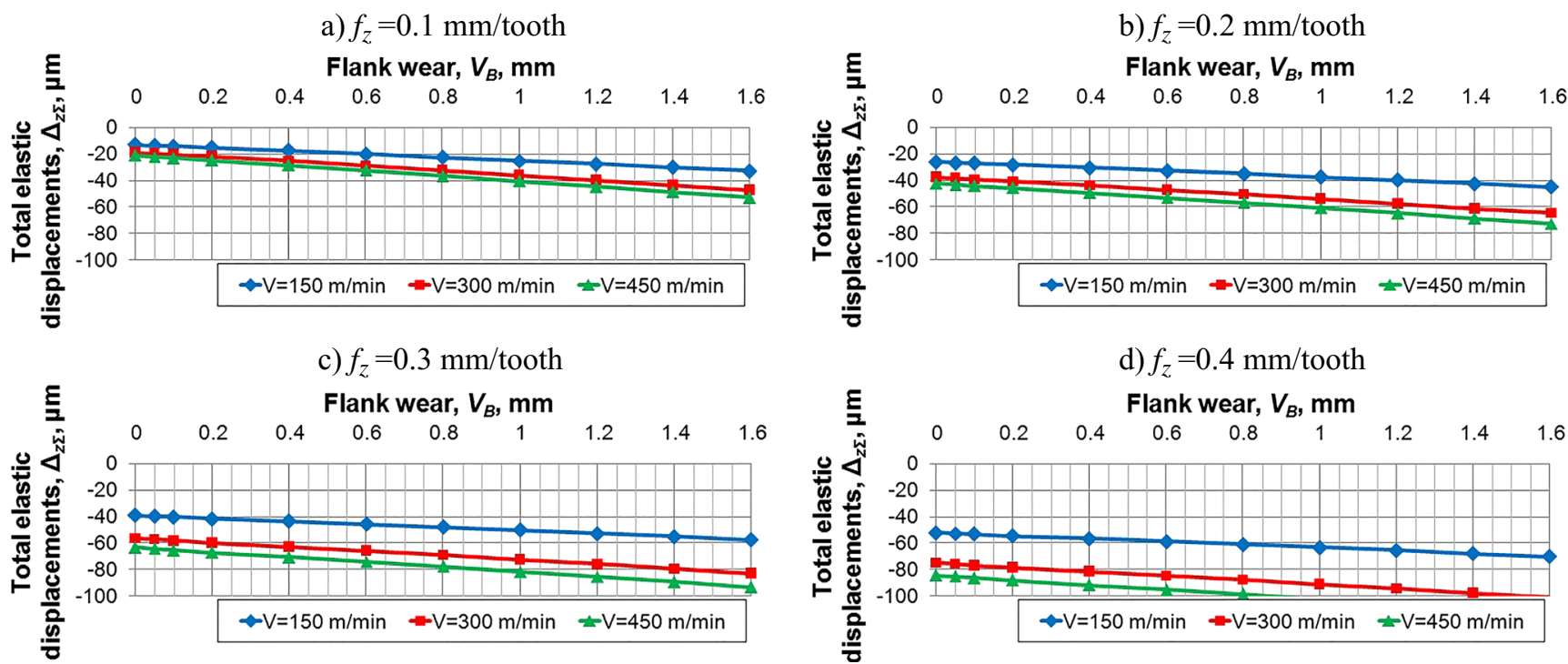

c) $f_{z}=0.3 \mathrm{~mm} /$ tooth

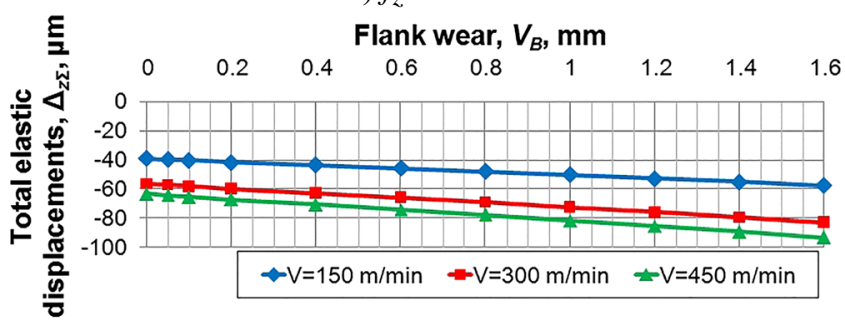

Fig. 11 Dependence of total elastic displacement in direction of executable dimension on flank wear value for different cutting speeds (45 steel, $D=200 \mathrm{~mm}, z=20, B=120 \mathrm{~mm}, t=1 \mathrm{~mm}, l o / D=1, k r=60^{\circ}$ ) 
a) $f_{z}=0.1 \mathrm{~mm} /$ tooth

Flank wear, $V_{B}, \mathrm{~mm}$

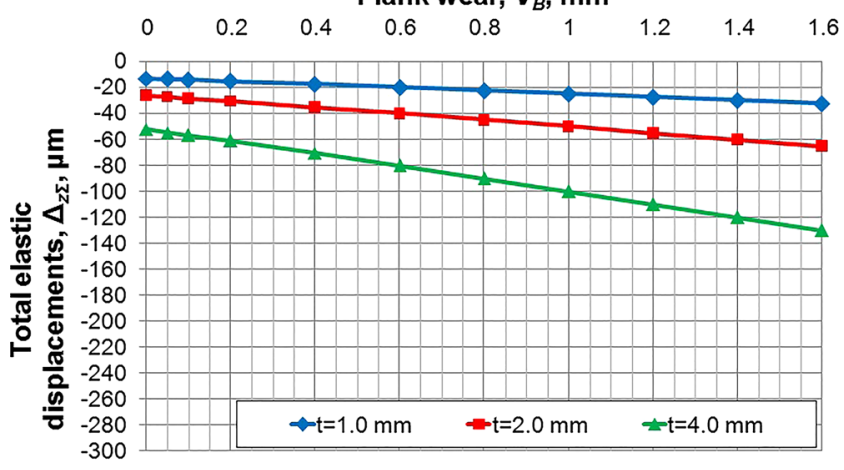

c) $f_{z}=0.3 \mathrm{~mm} /$ tooth

Flank wear, $V_{B}, \mathrm{~mm}$

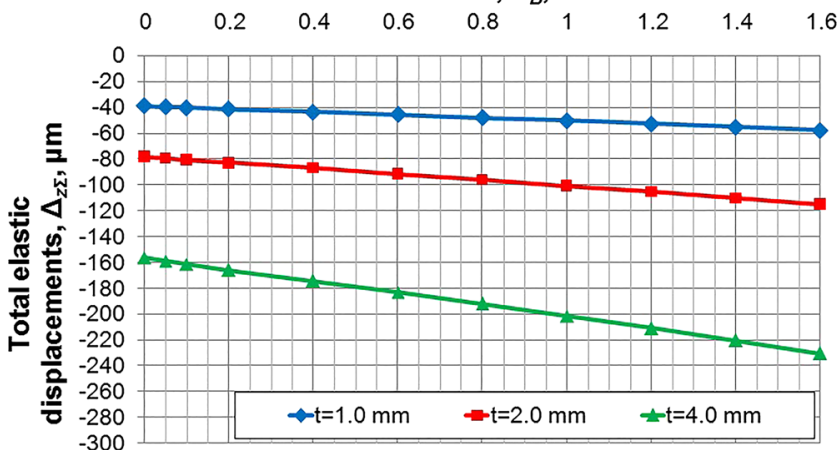

b) $f_{z}=0.2 \mathrm{~mm} /$ tooth

Flank wear, $V_{B}, \mathbf{m m}$

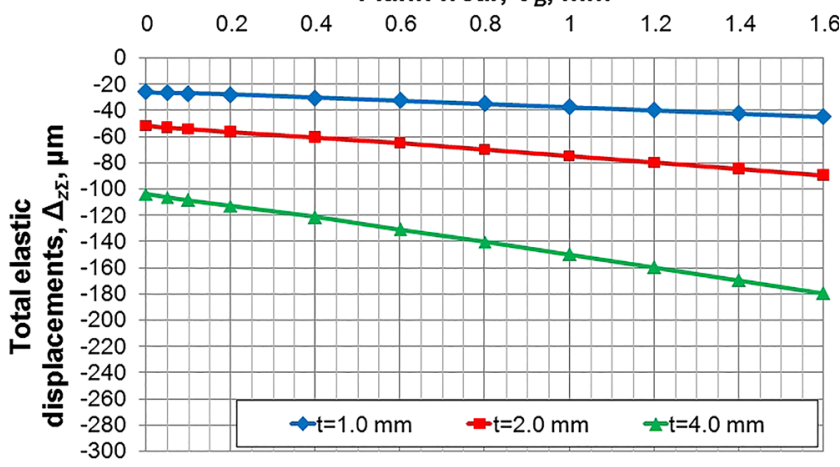

d) $f_{z}=0.4 \mathrm{~mm} /$ tooth

Flank wear, $V_{B}, \mathbf{m m}$

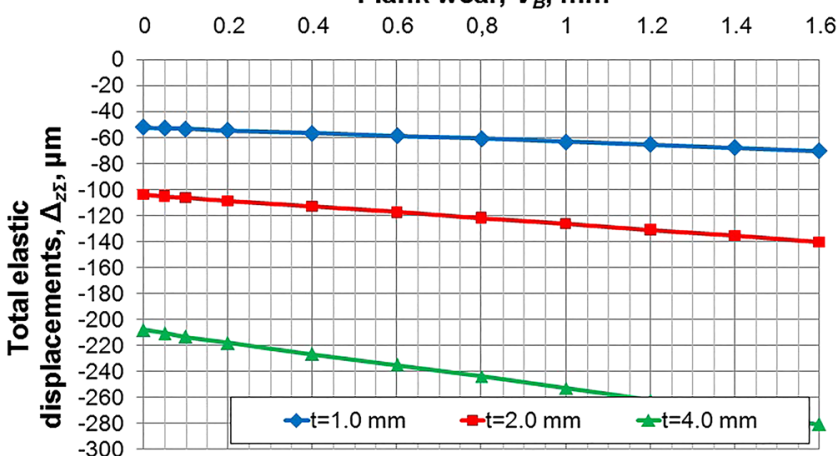

Fig. 12 Dependence of total elastic displacement in direction of executable dimension on flank wear value for different cutting depths (45 steel, $\left.D=200 \mathrm{~mm}, z=20, B=120 \mathrm{~mm}, l o / D=1, k r=60^{\circ}, V=150 \mathrm{~m} / \mathrm{min}\right)$

system-processing parameters (different workpiece materials, cutting speeds, cutting depths, different main cutting-edge angles, and the cutter overhangs) as shown in Table 5 for the straight part of the tooth cutting edge, i.e., for the point radius $r_{0}=0$.

a) $f_{z}=0.1 \mathrm{~mm} /$ tooth

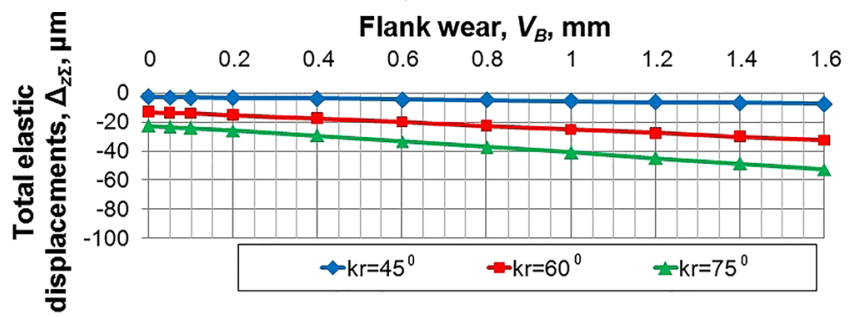

c) $f_{z}=0.3 \mathrm{MM}$

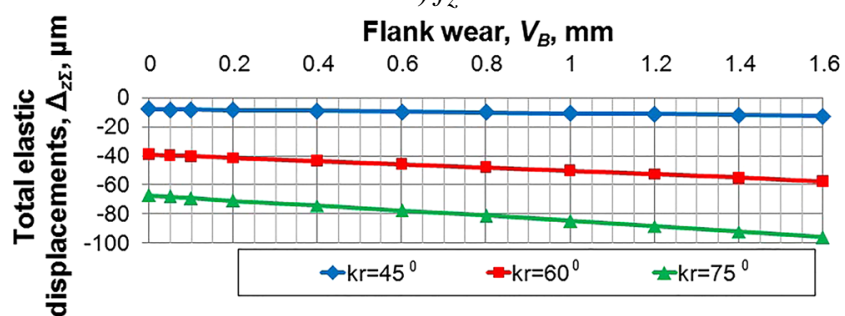

The workpiece materials considered in this work are the following steel grades which are used frequently in face milling [40, 41]: carbon steels (GOST 1050-88) - 45 steel; chromium steels (GOST 4543-71) - 40H steel; and chromium nickel wolfram steel (GOST 4543-48)—18HNVA steel. The

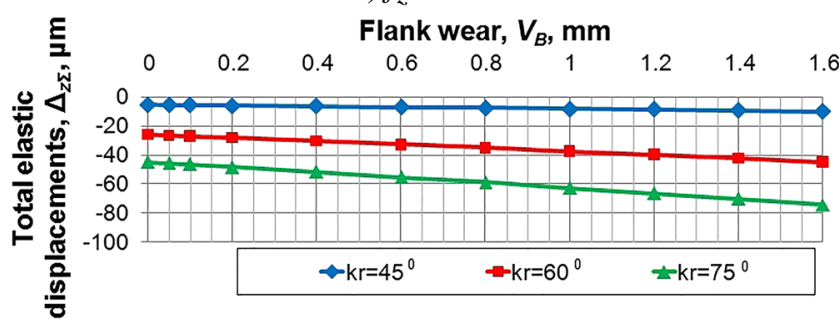

d) $f_{z}=0.4 \mathrm{~mm} /$ tooth

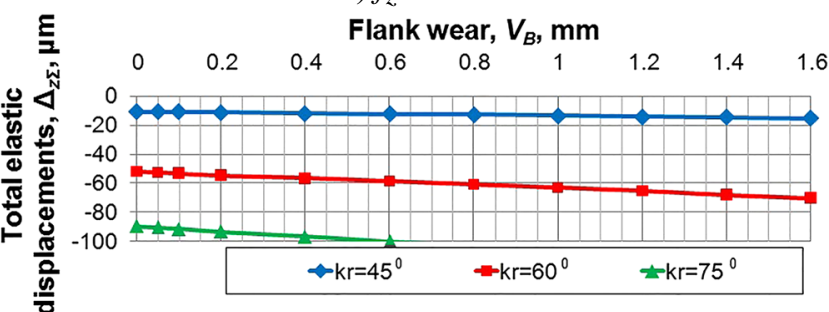

Fig. 13 Dependence of total elastic displacement in direction of executable dimension on the flank wear value for different approaching angles (45 steel, $D=200 \mathrm{~mm}, z=20, B=120 \mathrm{~mm}, t=1 \mathrm{~mm}, l o / D=1, V=150 \mathrm{~m} / \mathrm{min})$ 
a) $f_{z}=0.1 \mathrm{~mm} /$ tooth

Flank wear, $V_{B}, \mathrm{~mm}$

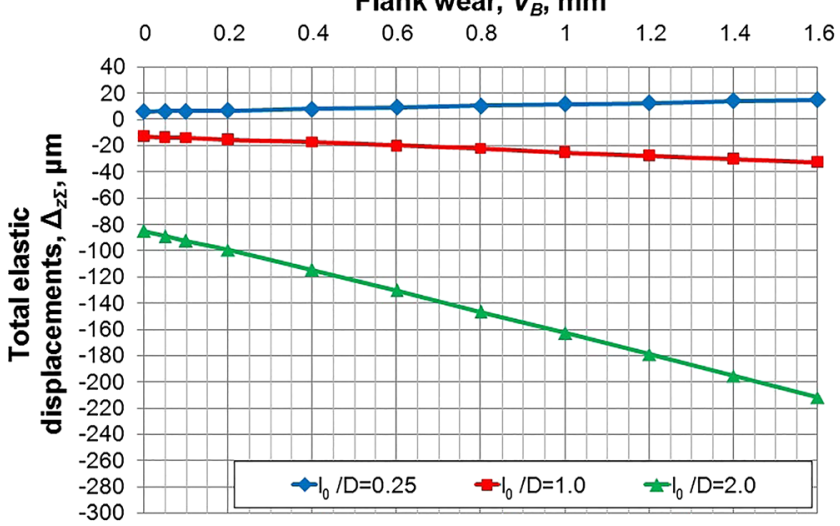

c) $f_{z}=0.3 \mathrm{~mm}$

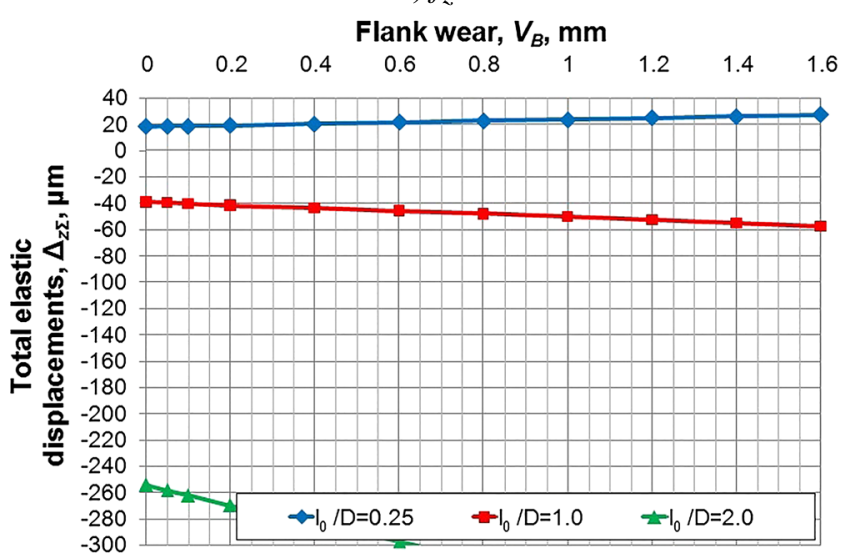

b) $f_{z}=0.2 \mathrm{~mm} /$ tooth

Flank wear, $V_{B}, \mathrm{~mm}$

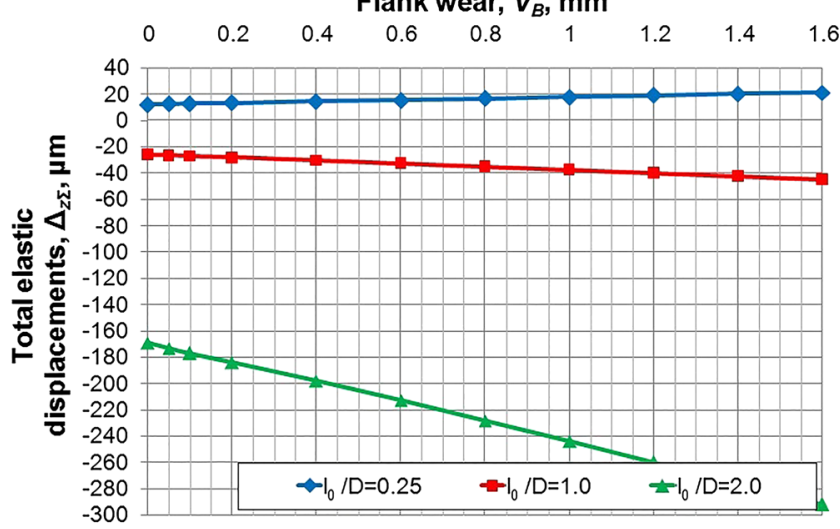

d) $f_{z}=0.4 \mathrm{~mm} /$ tooth

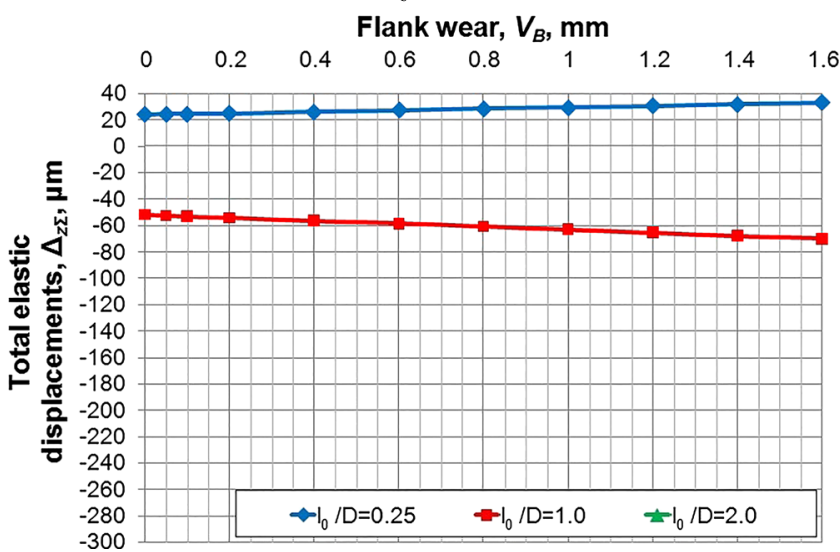

Fig. 14 Dependence of total elastic displacement in direction of executable dimension on flank wear value for different cutter overhangs (45 steel, $D=200 \mathrm{~mm}, z=20, B=120 \mathrm{~mm}, t=1 \mathrm{~mm}, k r=60^{\circ}, V=150 \mathrm{~m} / \mathrm{min}$ )

chemical compositions of these materials are defined in Table 6 [40].

\subsection{The impact of cutting parameters and tool wear on elastic displacements of the technological system}

Figures 10, 11, 12, 13, and 14 show the variations of the calculated total elastic displacements of the technological system with respect to tool flank wear for different processed materials cutting speed, depth of cut, different main cuttingedge angles, and the ratio of the cutter overhang to its diameter.

Let us analyze the obtained graphic dependencies of the technological system displacements in the direction of the executable dimension. The impact of the flank wear value on the total elastic displacement in the direction of executable dimension $\Delta_{Z \Sigma}$ for different treated materials is given in Table 7 (also see Fig. 10).

Therefore, the increase of total elastic displacements $\Delta_{z \Sigma}$ at $V_{B}=1.6 \mathrm{~mm}$ compared to the bar blade $\left(V_{B}=0\right)$ for $40 \mathrm{X}$ steel is $10.2-10.5 \%$, for $18 \mathrm{XHBA}$ steel, and $21.5-22.5 \%$ compared to 45 steel.
Dependence of the total elastic displacement in the direction of the executable dimension on the flank wear value for different cutting speeds is shown in Fig. 11.

The increase of the total elastic displacement in the direction of the executable dimension $\Delta_{Z \Sigma}$ for worn tool (at maximum value of $V_{B}$ ) compared to fresh tool for different cutting speeds is shown in Table 8 (also see Fig. 11).

Therefore, the increase of total elastic displacements $\Delta_{Z \Sigma}$ at $V_{B}=1.6 \mathrm{~mm}$ compared to the bar blade $\left(V_{B}=0\right)$ at the

Table 7 Impact of tool flank wear (at max. value of $V_{B}$ ) on total elastic displacement for different treated materials

\begin{tabular}{lllll} 
Treated material & \multicolumn{3}{l}{$\begin{array}{l}\text { Increase of total elastic displacements } \Delta_{z \Sigma} \text { by } \\
\text { at } V_{B}=1.6 \mathrm{~mm} \text { compared to bar blade }\left(V_{B}=0\right)\end{array}$} \\
\cline { 2 - 5 } & \multicolumn{2}{l}{ Feed per tooth, $f_{z}$, mm/tooth } \\
\cline { 2 - 5 } & 0.1 & 0.2 & 0.3 & 0.4 \\
\hline 45 steel & 19.5 & 18.9 & 18.6 & 18.2 \\
40X steel & 21.5 & 20.9 & 20.4 & 20.0 \\
18XHBA steel & 23.7 & 23.2 & 22.5 & 22.3 \\
\hline
\end{tabular}


Table 8 Impact of flank wear on total elastic displacement for different cutting speeds

Cutting speed, Increase of total elastic displacements $\Delta_{Z \Sigma}$ by _ $\mu \mathrm{m}$

$V, \mathrm{~m} / \mathrm{min} \quad$ at $V_{B}=1.6 \mathrm{~mm}$ compared to bar blade $\left(V_{B}=\overline{0}\right)$

\begin{tabular}{lllll}
\cline { 3 - 4 } & \multicolumn{4}{l}{ Feed per tooth, $f_{z}, \mathrm{~mm} /$ tooth } \\
\cline { 2 - 5 } & 0.1 & 0.2 & 0.3 & 0.4 \\
\hline 150 & 19.5 & 18.9 & 18.6 & 18.2 \\
300 & 28.2 & 27.2 & 26.6 & 26.2 \\
450 & 31.6 & 30.6 & 30 & 29.4 \\
\hline
\end{tabular}

cutting speed $V=450 \mathrm{~m} / \mathrm{min}$ and cutting speed $V=300 \mathrm{~m} / \mathrm{min}$ is $61.5-62 \%$ and $43.9-44.6 \%$, respectively, compared to the cutting speed $V=150 \mathrm{~m} / \mathrm{min}$.

Dependence of the total elastic displacement in the direction of executable dimension on the flank wear value for different cutting depths is shown in Fig. 12.

The increase of the total elastic displacement in the direction of executable dimension $\Delta_{Z \Sigma}$ due to increase of flank wear for different cutting depths is given in Table 9 (see Fig. 12).

Therefore, the increase of total elastic displacements $\Delta_{Z \Sigma}$ for $V_{B}=1.6 \mathrm{~mm}$ compared to the bar blade $\left(V_{B}=0\right)$ at cutting depth $t=4 \mathrm{~mm}$ and $2 \mathrm{~mm}$ is 400 and $200 \%$, respectively, compared to that of cutting depth $t=1 \mathrm{~mm}$.

Dependence of the total elastic displacement in the direction of executable dimension on the flank wear value for different approaching angles is shown in Fig. 13.

The impact of the flank wear value on the total elastic displacement in the direction of the executable dimension $\Delta_{Z \Sigma}$ for different approaching angles is given in Table 10 (see Fig. 13).

Therefore, the increase of total elastic displacements $\Delta_{Z \Sigma}$ at $V_{B}=1.6 \mathrm{~mm}$ compared to the bar blade $\left(V_{B}=0\right)$ at the main cutting-edge angle $k_{r}=60^{\circ}$ and $75^{\circ}$ is $404-406 \%$ and $628-629 \%$ compared to that at the main cutting-edge angle $k_{r}=45^{\circ}$. At the main cutting-edge angle $k_{r}=45^{\circ}$, plane-parallel and angular

Table 9 Impact of the flank wear on total elastic displacement for different cutting depths

Cutting depth, $t$, мм $\quad$ Increase of total elastic displacements $\Delta_{Z \Sigma}$ by $\_\mu \mathrm{m}$ at $V_{B}=1.6 \mathrm{~mm}$ compared to bar blade $\left(V_{B}=0\right)$

Feed per tooth, $f_{z}, \mathrm{~mm} /$ tooth

\begin{tabular}{lllll}
\cline { 2 - 5 } & 0.1 & 0.2 & 0.3 & 0.4 \\
\hline 1 & 19.5 & 18.9 & 18.6 & 18.2 \\
2 & 39.0 & 37.9 & 37 & 36.5 \\
4 & 77.9 & 75.7 & 73.9 & 72.7 \\
\hline
\end{tabular}

Table 10 Impact of flank wear on total elastic displacement for different approaching angles

Main cutting-edge Increase of total elastic displacements $\Delta_{Z \Sigma} \ldots \mu \mathrm{m}$ angle, $\mathrm{kr}$, deg at $V_{B}=1.6 \mathrm{~mm}$ compared to bar blade $\left(V_{B}=0\right)$

\begin{tabular}{rrrrr}
\multicolumn{5}{c}{ Feed per tooth, $f_{z}$, mm/tooth } \\
\cline { 2 - 5 } & \multicolumn{1}{c}{0.1} & \multicolumn{1}{l}{0.2} & \multicolumn{1}{l}{0.3} & \multicolumn{1}{c}{0.4} \\
\hline 45 & 4.8 & 4.7 & 4.6 & 4.5 \\
60 & 19.5 & 18.9 & 18.6 & 18.2 \\
75 & 30.2 & 29.3 & 28.7 & 28.3 \\
\hline
\end{tabular}

displacements have different signs for the same values of the total displacement, and as the result, the total elastic displacement comes to zero as seen in Fig. 13.

Dependence of the total elastic displacement in direction of executable dimension on the flank wear value for different cutter overhang to diameter ratios is shown in Fig. 14.

The impact of the flank wear value on the total elastic displacement in the direction of executable dimension $\Delta_{Z \Sigma}$ at different cutter overhangs is given in Table 11 (see Fig. 14).

Therefore, the increase of total elastic displacements $\Delta_{Z \Sigma}$ at $V_{B}=1.6 \mathrm{~mm}$ compared to the bar blade $\left(V_{B}=0\right)$ for the cutter overhang to diameter ratio $l_{o} /$ $D=2$ and 1 is $1391-1401 \%$ and $214-217 \%$, respectively, compared to that of the cutter overhang to diameter ratio $l_{o} / D=0.25$. At the cutter overhang to diameter ratio $l_{o} / D=0.25$, the angular displacements are close to zero, and then the total displacements only include plane-parallel displacements (see Fig. 14).

For all the calculated values (Tables 7, 8, 9, 10, and 11), the increase of total elastic displacements $\Delta_{Z \Sigma}$ at $V_{B}=1.6 \mathrm{~mm}$ compared to the bar blade $\left(V_{B}=0\right)$ for the feed per tooth $0.1,0.2$, and 0.3 is $5-6 \%, 3-4 \%$, and $1-2 \%$, respectively, compared to that at the feed of $0.4 \mathrm{~mm} /$ tooth.

Table 11 Impact of flank wear on total elastic displacement at different cutter overhangs

\begin{tabular}{lccrc}
\hline $\begin{array}{l}\text { The cutter overhang to } \begin{array}{l}\text { Increase of total elastic displacements } \Delta_{Z \Sigma} \\
\text { diameter ratio, } l_{o} / D\end{array} \\
\text { by } \mu \text { at } V_{B}=1.6 \text { mM compared to bar } \\
\text { blade }\left(V_{B}=0\right)\end{array}$ \\
\cline { 2 - 5 } & \multicolumn{2}{l}{ Feed per tooth, $f_{z}$, mm/tooth } \\
\cline { 2 - 5 } & 0.1 & 0.2 & 0.3 & 0.4 \\
\hline 0.25 & 9.0 & 8.8 & 8.6 & 8.5 \\
1 & 19.5 & 18.9 & 18.6 & 18.2 \\
2 & 126.8 & 123 & 120.3 & 118.3 \\
\hline
\end{tabular}




\section{Conclusions}

This paper proposed a method to estimate total elastic deformations of the technological system in face milling process by consideration of tool flank wear along with machining process parameters. Following conclusions can be made from this analysis.

(1) The total elastic displacement which combines axial and angular deformations has been shown to be influenced by face milling machining parameters (workpiece material, cutting speed, cutting depth, the main cutting-edge angle, the cutter overhang to its diameter ratio, feed per tooth) and different values of the tool flank wear during machining.

(2) Increase of the face mill teeth flank wear leads to a significant increase of elastic deformations of the technological system, in the direction of the executable dimension.

(3) Experimental values of total elastic displacement at different tool flank wear agree well with the mathematical model to validate the adequacy of the proposed model prediction.

(4) The paper presents the methods and experimental research on determining the axial and angular compliances of the CNC GF2171S5 milling machine technological system. However, the experimental method is applicable for other machine tools and materials.

Acknowledgments We thank Mary Ilieva, Chelyabinsk, Russia, for the preliminary translation of the article into English. The authors also honor the memory of deceased Prof. Anatoly Koshin, Chelyabinsk, Russia, as it was he who helped them with the mathematical formulation of their studies several years ago. The research was carried out within the South Ural State University Project 5-100 from 2016 to 2020 aimed to increase the competitiveness of leading Russian universities among the world research and educational centers. The work was supported by Act 211 Government of the Russian Federation, contract no. 02.A03.21.0011.

Open Access This article is distributed under the terms of the Creative Commons Attribution 4.0 International License (http:// creativecommons.org/licenses/by/4.0/), which permits unrestricted use, distribution, and reproduction in any medium, provided you give appropriate credit to the original author(s) and the source, provide a link to the Creative Commons license, and indicate if changes were made.

\section{References}

1. Zhenyu S, Luning L, Zhanqiang L (2015) Influence of dynamic effects on surface roughness for face milling process. Int $\mathrm{J}$ Adv Manuf Technol 80(9-12):1823-1831. doi:10.1007/s00170-0157127-x

2. Simunovic K, Simunovic G, Saric T (2013) Predicting the surface quality of face milled aluminium alloy using a multiple regression model and numerical optimization. Meas Sci Rev 13(5):265-272. doi:10.2478/msr-2013-0039
3. Khomenko VA, Cherdancev AO, Cherdancev PO, Goncharov VD, Kulawik A (2016) Analysis of the face milling process based on the imitation modelling. IOP Conf Ser: Mater Sci Eng 126(1):012001. doi:10.1088/1757-899X/126/1/012001

4. Kolev KS, Gorchakov LM (1976) Precision machining and cutting. Moscow, Mashinostroenie, $144 \mathrm{p}$

5. Medvedev DD (1973) Accuracy of processing in small-quantity production. Moscow, Mashinostroenie, $120 \mathrm{p}$

6. Radulescu R, Kapoor SG, DeVor RE (1997) An investigation of variable spindle speed face milling for tool-work structures with complex dynamics, part 2: physical explanation. Journal of Manufacturing Science and Engineering, Transactions of the ASME 119(3):273-280

7. Denkena B, Köhler J, Hasselberg E (2013) Modeling of workpiece shape deviations in face milling of parallel work piece compounds. Procedia CIRP 8:176-181. doi:10.1016/j.procir.2013.06.085

8. Denkena B, Hasselberg E (2015) Influence of the cutting tool compliance on the workpiece surface shape in face milling of workpiece compounds. Procedia CIRP 31:7-12. doi:10.1016/j.procir.2015.03. 074

9. Badar MA, Raman S, Pulat PS (2005) Experimental verification of manufacturing error pattern and its utilization in form tolerance sampling. Int J Mach Tools Manuf 45(1):63-73. doi:10.1016/j. ijmachtools.2004.06.017

10. Hadad M, Ramezani M (2016) Modeling and analysis of a novel approach in machining and structuring of flat surfaces using face milling process. Int J Mach Tools Manuf 105:32-44. doi:10.1016/j. ijmachtools.2016.03.005

11. Huang Y, Hoshi T (2001) Optimization of fixture design with consideration of thermal deformation in face milling. J Manuf Syst 19(5):332-340

12. Huang Y, Hoshi T (1999) Optimization on fixture design for plate shaped work piece in terms of flatness error due to cutting heat in finish face milling. Seimitsu Kogaku Kaishi/Journal of the Japan Society for Precision Engineering 65(2):229-233

13. Tai BL, Wang H, Nguye H, Hu SJ, Shih A (2012) Surface variation reduction for face milling based on high-definition metrology. ASME 2012 International Manufacturing Science and Engineering Conference Collocated with the 40th North American Manufacturing Research Conference and in Participation with the Int. Conf. MSEC 2012:715-724. doi:10. 1115/MSEC2012-7208

14. Tai BL, Stephenson DA, Shih AJ (2011) Improvement of surface flatness in face milling based on 3-D holographic laser metrology. Int J Mach Tools Manuf 51(6):483-490. doi:10.1016/j.ijmachtools. 2011.02.006

15. Tai BL, Stephenson DA, Shih AJ (2009) Improvement of surface flatness in face milling by varying the tool cutting depth and feed rate. Proceedings of the ASME International Manufacturing Science and Engineering Conference 2009, MSEC2009, 2: 73-79. doi:10.1115/MSEC2009-84208

16. Franco P, Estrems M, Faura F (2008) A study of back cutting surface finish from tool errors and machine tool deviations during face milling. Int J Mach Tools Manuf 48(1):112-123. doi:10.1016/j. ijmachtools.2007.07.001

17. Yi W, Jiang ZL, Li Z (2014) Effect of different machining parameters on time-dependent flatness (2014) App Mech Mater 670-671: 502-505. doi:10.4028/www.scientific.net/AMM.670-671.502

18. Sheth S, George PM (2016) Experimental investigation and prediction of flatness and surface roughness during face milling operation of WCB material. Procedia Technology 3:344-351. doi:10.1016/j. protcy.2016.03.036

19. Kaldestad KB, Tyapin I, Hovland G (2015) Robotic face milling path correction and vibration reduction. IEEE/ASME International Conference on Advanced Intelligent Mechatronics, AIM, 2015- 
August, art. no. 7222591: 543-548. doi:10.1109/AIM.2015. 7222591

20. Tyapin I, Kaldestad KB, Hovland G (2015) Off-line path correction of robotic face milling using static tool force and robot stiffness. IEEE International Conference on Intelligent Robots and Systems, 2015-December, art. no. 7354157: 5506-5511. doi:10.1109/IROS. 2015.7354157

21. Yi W, Jiang Z, Shao W, Han X, Liu W (2015) Error compensation of thin plate-shape part with prebending method in face milling. Chin J Mech Eng En 28(1):88-95. doi:10.3901/CJME.2014.1120.171

22. Yi W, Jiang Z, Li Z, Li B, Liu W (2014) The influence of stretched fixation on face milling-machined 6061T6 aluminum alloy. Key Eng Mater 589-590:264-268. doi:10.4028/www.scientific.net/ KEM.589-590.264

23. Davoudinejad A, Annoni M, Rebaioli L, Semeraro Q (2014) Improvement of surface flatness in high precision milling. Conference Proceedings - 14th International Conference of the European Society for Precision Engineering and Nanotechnology, EUSPEN 2014 2: 190-193.

24. Nguyen HT, Wang H, Tai BL, Ren J, Jack Hu S, Shih A (2016) High-definition metrology enabled surface variation control by cutting load balancing. J Manuf Sci E-T ASME 138(2): [021010]). doi: 10.1115/1.4030782

25. Nguyen HT, Wang H, Hu SJ (2014) High-definition metrology enabled surface variation control by reducing cutter-spindle deflection. ASME 2014 International Manufacturing Science and Engineering Conference, MSEC 2014 Collocated with the JSME 2014 International Conference on Materials and Processing and the 42nd North American Manufacturing Research Conference 1. doi: 10.1115/MSEC2014-4017

26. Shamoto E, Mori T, Nishimura K, Hiramatsu T, Kurata Y (2010) Suppression of regenerative chatter vibration in simultaneous double-sided milling of flexible plates by speed difference. CIRP Ann Manuf Technol 59(1):387-390. doi:10.1016/j.cirp.2010.03.028

27. Mori T, Hiramatsu T, Shamoto E (2011) Simultaneous double-sided milling of flexible plates with high accuracy and high efficiencysuppression of forced chatter vibration with synchronized singletooth cutters. Precis Eng 35(3):416-423. doi:10.1016/j. precisioneng.2011.02.002

28. Gu F, Melkote SN, Kapoor SG, Devor RE (1997) A model for the prediction of surface flatness in face milling. J Manuf Sci E-T ASME 119(4 PART I): 476-484.: A.
29. Liu EA, Zou Q (2011) Machined surface error analysis a face milling approach. J Adv Manuf Syst 10(2):293-307. doi:10.1142/ S0219686711002211

30. Nguyen HT, Wang H, Hu SJ (2014) Modeling cutter tilt and cutterspindle stiffness for machine condition monitoring in face milling using high-definition surface metrology. Int J Adv Manuf Technol 70(5-8):1323-1335. doi:10.1007/s00170-013-5347-5

31. Medvedev DD (1973) Refined method of determination of the rigidity of a technological system. [Utochnennyi metod opredeleniya zhestkosti tekhnologicheskoi sistemy]. Izv Vyssh Uchebn Zaved Mashinostr (9): 188-191.

32. Bazrov BM (1973) Adaptive control gives more accurate machining of axially-symmetrical parts. Mach Tool 44(3):13-17

33. Bazrov BM, Novikov OA (1983) Selection of milling rates for maximum metal removal with given accuracy. Soviet Eng Res 3(11):91-94

34. Pimenov DY, Guzeev VI, Koshin AA (2011) Elastic displacement of a technological system in face milling with tool wear. Rus Eng Res 31(11):1105-1109. doi:10.3103/S1068798X11110219

35. Guzeev VI, Pimenov DY (2011) Cutting force in face milling with tool wear. Rus Eng Res 31(10):989-993. doi:10.3103/ S1068798X11090139

36. Pimenov DY, Guzeev VI (2017) Mathematical model of plowing forces to account for flank wear using FME modeling for orthogonal cutting scheme. Int J Adv Manuf Technol 89(9):3149-3159. doi:10.1007/s00170-016-9216-x

37. D'yakonov AA (2012) Improvement of grinding speeds by assessing the machinability of materials. Rus Eng Res 32(7-8): 604-607. doi:10.3103/S1068798X12060068

38. Sokolovskii AT (1956) Zhestkost' V Tekhnologii Mashinostroeniya (rigidity in manufacturing technology). Moscow: Mashgiz, $396 \mathrm{p}$.

39. Loladze TN (1982) Prochnost' i iznosostoikost' rezhushchego instrumenta (strength and wear resistance of cutting tools). Mashinostroenie, Moscow

40. Handbook Metallist: Handbook in 5 volumes. Volume 2 / Ed. AG Rahshtadta, VA Brostrema. Moscow: Mashinostroenie, (1976) 720 p.

41. Guzeev VI, Batuev VA, Surkov IV (2005) Cutting regimes for turning and mill-boring machines with program numerical control. Mashinostroenie, Spravochnik, Guzeev VI, Ed, Moscow 